\title{
Gonioscopy: A Review
}

\section{Parul Singh, Manoj Tyagi, Yogesh Kumar, Krishna Kuldeep, Parmeshwari Das Sharma}

V. C. S. G. G. M. S. \& R. I., Srinagar, India.

Email: parulophtha@gmail.com

Received January $23^{\text {rd }}, 2013$; revised February $24^{\text {th }}, 2013$; accepted March $15^{\text {th }}, 2013$

Copyright (C) 2013 Parul Singh et al. This is an open access article distributed under the Creative Commons Attribution License, which permits unrestricted use, distribution, and reproduction in any medium, provided the original work is properly cited.

\begin{abstract}
Gonioscopy allows us to examine the angle of anterior chamber and forms part of complete ophthalmic examination and it is mandatory for the diagnosis and management of glaucoma. Gonioscopy permits the identification of eyes at risk for closure and detects angle abnormalities that could have diagnostic and therapeutic implications. Principle, types and techniques of gonioscopy, various types of gonioscopic lenses used, indications of performing gonioscopy, gonioscopic anatomy and grading are discussed in this article.
\end{abstract}

Keywords: Gonioscopy; Anterior Chamber Angle; Goniolens

\section{Introduction}

Gonioscopy is the examination of the angle of the anterior chamber and is mandatory for the management of glaucoma. Gonioscopy permits the identification of eyes at risk for closure and detects angle abnormalities that could have diagnostic and therapeutic implications. Principle, types and techniques of gonioscopy, various types of gonioscopic lenses used, indications of performing gonioscopy, gonioscopic anatomy and grading are discussed in this article.

\section{Evolution of Gonioscopy}

The term "Gonioscopy" was coined by Trantas in 1907 $[1,2]$, while Salzmann was the first person to study the optics behind gonioscopy and to use lens for viewing angle in 1914 [1,2]. He is thus known as "Father of Gonioscopy". In 1919, Koeppes used the zeiss slit-lamp to examine angle with his newly developed direct contact lens [3]. Trancoso is credited for development of a self-illuminating monocular gonioscope in 1925 [4]. It was approximately two years later in 1927 that the angle was first photographed by Thorburn [5]. Gonioprism was introduced by Goldmann in 1938. It was Barkanwho established the use of gonioscopy in goniotomy [6$8]$.

\section{Principle of Gonioscopy}

Without a gonioscope, the rays coming from the anterior chamber angle strikes the corneal interface at an angle that exceeds the critical angle, and is thus totally internally reflected. The gonioscope lens changes the interface from cornea-air to lens-air, changing the critical angle, thus permitting viewing of angle.

\section{Techniques of Gonioscopy}

\subsection{Direct Gonioscopy}

Direct gonioscopy is performed with gonioscopic lenses used with portable slit-lamp or an operating microscope. It is done in supine position after instilling topical anaesthesia, though it can be done under general anaesthesia too. Goniolensis positioned on cornea using a bridge of balanced salt solution and viscous preparation. Examiner holds goniolens in one hand and light source in another during the procedure. It provides panoramic view of the entire circumference and is very useful to compare the angles of two eyes by looking at them simultaneously. It can also be used for goniotomy and gonio-synechialysis.

\subsection{Indirect Gonioscopy}

Indirect gonioscopy uses mirrors or prisms to overcome the problem of total internal reflection. Patient is positioned on slit lamp and topical anaesthesia is instilled. Gonioprismis placed against cornea with or without use of fluid as bridging agent and rotated to see angles using slit-lamp illumination and magnification. 
5. Direct vs Indirect Gonioscopy: Advantages and Disadvantages

\begin{tabular}{ll}
\hline \multicolumn{1}{c}{ Direct gonioscopy } & \multicolumn{1}{c}{ Indirect gonioscopy } \\
\hline $\begin{array}{l}\text { The procedure is done in supine } \\
\text { position. }\end{array}$ & $\begin{array}{l}\text { The procedure is done in } \\
\text { sitting position. }\end{array}$ \\
$\begin{array}{l}\text { Provides less magnification as } \\
\text { compared to indirect gonioscopy. }\end{array}$ & $\begin{array}{l}\text { Provides more magnification } \\
\text { of the two procedures. }\end{array}$ \\
$\begin{array}{l}\text { Patient is more comfortable } \\
\text { during procedure. }\end{array}$ & Lesser patient comfort. \\
$\begin{array}{l}\text { Binocular comparison is possible } \\
\text { in direct gonioscopy. }\end{array}$ & $\begin{array}{l}\text { Binocular comparison is not } \\
\text { The procedure can be used for } \\
\text { goniotomy and } \\
\text { goniosynechialysis. }\end{array}$ \\
\hline
\end{tabular}

Direct gonioscopy is performed with steep convex lenses used along with portable slit-lamp or an operating microscope. This procedure has its significance in simultaneous observation and comparison of bilateral anterior chamber angles. This is essentially used for examination of children under anaesthesia and for surgical procedures like goniotomy. Indirect gonioscopy uses mirrors or prism along with slit-lamp to examine angle of anterior chamber. This is a procedure useful even in out patient department for examination of angle of anterior chamber.

\section{Types of Gonioscopic Lenses}

\subsection{Direct Gonioscopic Lenses}

- Koeppes: prototype diagnostic lens.

- Richardson Shaffer: infants.

- Layden: premature infants.

- Hoskins Barkan: prototype surgical.

- Thorpe: surgical/diagnostic in operation theatre.

- Swan Jacob: surgical for children.

\subsection{Indirect Gonioscopic Lenses}

- Goldmann single mirror has one mirror inclined at $62^{\circ}$.

- Goldmann three-mirror has one mirror at $59^{\circ}$ for angle, other at $67^{\circ}$ for pars plana and, third one at $73^{\circ}$ for oraserrata.

- Zeiss four-mirror has four mirrors all at $64^{\circ}$ for angle.

- Posner four-mirror is like Zeiss four mirror gonioscopewith attached handle.

- Sussmann four-mirror: Handheld zeiss.

- Thorpe four-mirror has all mirrors placed at $62^{\circ}$.

- Ritchtrabeculoplasty lens has two mirrors at $59^{\circ}$ and two at $62^{\circ}$ with convex lens over the two.

\section{Gonioscopic Techniques for Step Iris Configuration and Narrow Angles}

\subsection{Manipulative Gonioscopy}

Manipulative gonioscopy is useful in studying angle anatomy in narrow irido-corneal angles. The angle chamber width is initially evaluated in primary gaze followed by observation of angle by asking patients to look into mirror with mirror tilted towards angle to be viewed.

\subsection{Indentation Gonioscopy}

The procedure is done with corneal type gonio-lenses that have small diameter. The central cornea is indented to force aqueous out and artificially widen the angle to view structures that were not visible before indentation. This was introduced by Forbe's [9]. The closure of the angle can be due to following causes:

- Synechial.

- Appositional.

- Optical.

Three things can happen on indentation:

- Iris moves peripherally backwards, assumes a concave configuration and angle recess widens. This represents appositional closure [10].

- Iris moves peripherally backward but periphery of the iris bulges and does not assume concave configuration. This represents an anteriorly displaced ciliary body and iris root, seen in plateau iris.

- The iris moves only slightly and evenly backward, but retains a convex profile. This can occur due to an anteriorly displaced lens or large diameter lens.

\section{Aims and Indications for Gonioscopy}

\subsection{Diagnostic Uses}

- For visualization of anterior chamber angle.

- Evidence of angle closure or narrow peripheral anterior chamber (Van Herricks).

- Classification of glaucoma.

- To look for any abnormality in angle-neovascularization angle recession, inflammation, tumor, degenerative ordevelo mental abnormality.

\subsection{Therapeutic Uses}

- Argon laser trabeculoplasty, selective laser trabeculoplasty.

- Goniotomy.

\section{Gonioscopic Anatomy}

While performing gonioscopy one can identify the structures from anterior to posterior and vice versa. The angle structures from anterior to posterior includes cornea, Schwalbe's line(termination of descemet's membrane), anterior non-pigmented trabecular network, the scleral spur, the ciliary body band, and the insertion into the ciliary body.

1) Cornea 
2) Schwalbe's line: This is the peripheral termination of the cornea where the Descemet's membrane ends. It can be best identified by locating the corneal wedge. Prominence of this line is known as posterior embryotoxon, seen in Axenfield Reiger's Anomaly. Pigments along this line are known as Sampaolesi's line, seen in pigmentary glaucoma and pseudo-exfoliation syndrome.

3) Trabecular meshwork: This has porous and textured appearance. Dispersed pigmentation is seen especially posteriorly which overlies Schlemm canal and is the functional portion meshwork. Pigmentation is prominent in inferior and nasal angle.

4) Scleral spur: It is a prominent internal extension of sclera which is whiter and less translucent compared to trabecular meshwork.

5) Ciliary body band: It is seen as light grey to dark brown band.

6) Iris: Following points are to be noted-configuration, concave, convex and insertion.

\section{Angles in Infants}

Normal infants have flat iris inserted posterior to scleral spur with little pigmentation in trabecular meshwork. A normal ciliary body band is present. In congenital glaucoma, the key finding is anterior insertion of iris, directly in the trabecular with thin ciliary body.

\section{Grading of Angle}

- Shaffer system.

- Scheie system.

- Spaeth system.

- RPC system.

\subsection{Shaffer System}

According to the Shaffer system, angle of anterior chamber can be graded as following.

\begin{tabular}{|c|c|c|}
\hline Grade $4\left(35^{\circ}-45^{\circ}\right)$ & $\begin{array}{l}\text { Ciliary body } \\
\text { band seen }\end{array}$ & Incapable of closure \\
\hline Grade $3\left(25^{\circ}-35^{\circ}\right)$ & Scleral spur seen & Incapable of closure \\
\hline Grade $2\left(20^{\circ}\right)$ & $\begin{array}{c}\text { Trabecular } \\
\text { meshwork seen }\end{array}$ & $\begin{array}{c}\text { Closure possible but } \\
\text { unlikely }\end{array}$ \\
\hline Grade $1\left(10^{\circ}\right)$ & $\begin{array}{c}\text { Schwalbe's line } \\
\text { seen }\end{array}$ & High risk of closure \\
\hline Grade $\mathrm{S}\left(<10^{\circ}\right)$ & $\begin{array}{l}\text { No iridocorneal } \\
\text { contact }\end{array}$ & Imminent closure \\
\hline Grade $\mathrm{O}\left(0^{\circ}\right)$ & No corneal wedge & $\begin{array}{l}\text { Indentation } \\
\text { gonioscopy }\end{array}$ \\
\hline
\end{tabular}

\subsection{Scheie System}

According to the Shaffer system, grading of angle of anterior chamber is as following.

\begin{tabular}{ccc}
\hline Grade 0 & CBB seen & No angle closure \\
Grade I & CBB Narrow & No angle closure \\
Grade II & CBB not seen, SS & Rarely closure possible \\
Grade III & Post. TM not seen & Closure likely \\
Grade IV & $\begin{array}{c}\text { Schwalbe's line not } \\
\text { seen }\end{array}$ & Gonioscopically closed \\
\hline
\end{tabular}

\subsection{Spaeth System}

This system grades the angle as a combination of following findings:

Iris configuration:

q: Queer (concave peripheral iris).

r: Regularly straight iris.

$\mathrm{s}$ : Steeply concave iris.

Angular width: $10^{\circ}, 20^{\circ}, 30^{\circ}, 40^{\circ}$.

Level of iris insertion:

A: Anterior to schwalbe's line.

B: Just behind schwalbe's line.

C: At the scleral spur.

D: Deep angle CBB seen.

E: Extremely deep angle.

Iris process:

$\mathrm{U}$ : along angle recess.

$\mathrm{V}$ : upto trabecular meshwork.

W: uptoschwalbe's line.

Pigmentation of posterior trabecular meshwork:

0 : No visible pigmentation.

1+: Just perceptible pigmentation.

2+: Definite but mild.

$3+$ : Moderately dense.

4+: Dense black pigmentation.

\subsection{RPC System}

RPC system of grading of anterior chamber angle is as following:

Grade 0: Closed.

Grade 1: Schwalbe's.

Grade 2: Anterior (non-pigmented) TM.

Grade 3: Posterior pigmented TM.

Grade 4: Scleral spur.

Grade 5: Ciliary body band.

Grade 6: Root of Iris.

\section{Gonioscopic Findings in Various Disorders}

\subsection{Disorders Associated with Open Angle}

1) Iris process: Prominent iris processes are feature of Axenfeld Reiger's anomaly. Broken iris process are seen in angle recession [10].

2) Trauma: Angle recession-widening of ciliary body band. 
a) Foreign body in angle.

b) Hyphema in angle.

c) PAS, pigmentation.

3) Pigmentary glaucoma: Sampaolesi's line.

4) Pseudo exfoliation syndrome: White flaky material and pigmentation can be seen.

\subsection{Disorders Associated with Closed Angle}

1) Angle closure glaucoma shows narrow/closed angle. Peripheral anterior synechiae and gonio-synechiae may be present.

2) Mass in angle.

3) Angle blood vessels-neovascular vessels.

\subsection{Gonioscopy after Surgery}

1) After cataract surgery:

a) Internal aspect of the incision can be seen gonioscopically.

b) Pseudophakic chafing by haptic of posterior chamber lens protruding through peripheral iridectomy and resting in the angle.

2) After filtering surgery:

a) Inner aspect oflimbal fistula and drainage implant can be seen.

b) Iridectomy can be observed [11].

\section{BiometericGonioscopy}

This is new method for objective measurement of anterior chamber angle. The reticule ismounted on slit lamp X10 ocular and ruled in $0.1 \mathrm{~mm}$ units, which is used to measure the distance between insertion of the iris and Schwalbe's line in superior, inferior, nasal and temporal quadrants. If the angle is closed, a measurement of 0 is recorded, while an occludable angle is defined as one with an average measurement of $0.25 \mathrm{~mm}$ or less for the four quadrants.

\section{Disinfection of the Lens}

Guidelines by the American Academy of Ophthalmology [11]:

- Invert the contact lens.

- Wipe the lens with alcohol sponge.

- Fill concave area with 1:10 solution of household bleech.

- Leave for five minutes.

- Rinse with water.

\section{Conclusion}

At present, there are new techniques such as ultrasound bio microscopy and optical coherence tomography, avail- able to ophthalmologists for the evaluation of the iridocorneal angle. These techniques can describe the width of the angle and perhaps the risk of developing angle closure. Though they are excellent tools, they cannot replace gonioscopy as the basic investigation for the diagnosis of glaucoma. Gonioscopy not only tells whether the angle is open or closed but also underlying cause of the same in a very cost-effective manner. In fact, it would be rational to state that without reasonable proficiency in the basic technique of gonioscopy, one should not manage glaucoma patients.

\section{REFERENCES}

[1] P. Palmberg, "Gonioscopy in the Glaucoma," In: R. Ritch, M. B. Sheilds and T. Krupin, Eds., The Glaucomas, I: Basic Sciences, Vol. I, 2nd Edition, Mosby, St. Louis, 1996, pp. 455-469.

[2] G. Gorin, “Gonioscopy,” In: J. E. Cairns, Ed., Grune \& Stratton, Glaucoma, 1986, Vol. I, pp. 101-149.

[3] L. Koeppe, "Die Mikroskopie des Lebenden Kammerwinkelsimfokalenlichte der Gullstrandschen Nernstspaltlampe," Albercht von Graefes Arch Klin Ophthalmol, Vol. 101, 1919, pp. 48-66.

[4] M. U. Troncoso, "Gonioscopy with Electric Ophthalmoscope," New York Academy of Medicine, New York, 1921.

[5] T. Thorburn, "A Gonioscopical Study of Anterior Peripheral Synechiae in Primary Glaucoma," Svenska Lakaresallskapets Handligar, Vol. 53, 1927, pp. 252-291.

[6] O. Barkan, S. F. Boyle and S. Maisler, "On the Genesis of Glaucoma. An Improved Method Based on Slit Lamp Microscopy of the Angle of Anterior Chamber," American Journal of Ophthalmology, Vol. 19, 1936, pp. 209215.

[7] O. Barkan, "Glaucoma: Classification, Causes, and Surgical Control. Results of Microgonioscopic Research," American Journal of Ophthalmology, Vol. 21, 1938, pp. 1099-1117.

[8] O. Barkan, "Recent Advances in the Surgery of Chronic Glaucoma," American Journal of Ophthalmology, Vol. 20, 1937, pp. 1237-1245.

[9] M. Forbes, "Gonioscopy with Indentation: A Method for Distinguishing between Appositional Closure \& Synechial Closure," Archives of Ophthalmology, Vol. 76, No. 4, 1966, pp. 488-492. http://dx.doi.org/10.1001/archopht.1966.03850010490005

[10] J. T. Wilensky and D. G. Campbell, "Primary Angle Closure Glaucomas," In: Albert \& Jakobiec, Eds., Principles \& Practice of Ophthalmology, Vol. VI, WB Saunders Company, Philadelphia, 2000.

[11] W. L. M. Alward, "Gonioscopy in Glaucoma," The Requisite in Ophthalmology Mosby, 2000, pp. 26-45. 